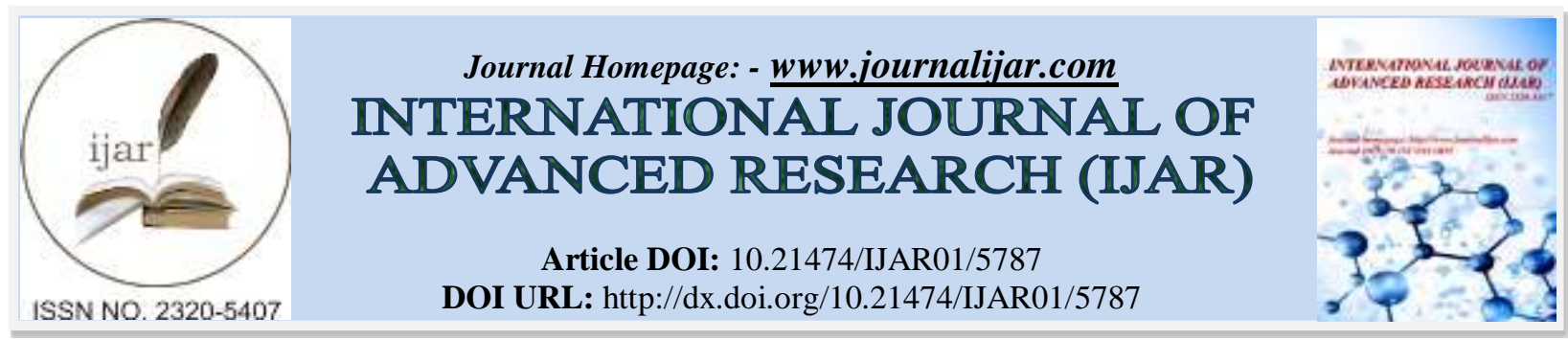

RESEARCH ARTICLE

\title{
“A RESPONSIBILITY OF EMPLOYEE PERFORMANCE IN ORGANISATION ON HUMAN RESOURCE DEVELOPMENT PROGRAMME".
}

\section{Dr. M. Devarajan and Dr. M. Vaanmalar.}

1. Assistant Professor, Department of corporate secretaryship, Erode Arts and Science College, Erode.

2. Assistant Professor, Department of corporate secretaryship, Hindusthan College of Arts and Science, Coimbatore.

\section{Manuscript Info}

\section{Manuscript History}

Received: 06 September 2017

Final Accepted: 08 October 2017

Published: November 2017

Key words:-

Human Resource Development,

Employee Performance, Programmes.

\begin{abstract}
Human Resource Development programme encompass numerous aspect of enable and empower human resources in organization. The effective performance of an organization depends not just on the available resources but its excellence and proficiency as required by the organization from time to time. Most of the good organization like manufacturing unit and an assortment of areas of administration depend on the stage of human resources development progrmmes. Human resource development programme is mainly concerned with developing the skills, knowledge, and competencies of people. Human Resource Development is a strategic and inclusive management area that involves establishing policies, practices, and administrative structures that focus on an organization's most valuable resource -- its people. Human Resource Development is the integrated use of systems, policies, and management practices to recruit, maintain, and develop employees in order for the organization to meet its desired goals.

This paper focuses in-depth into the issues related to consequence of human resource development programmes and its relation with employee performance in organizations.
\end{abstract}

Copy Right, IJAR, 2017,. All rights reserved.

\section{Introduction:-}

A Growth of human resources is essential for any organization that would like to be forceful and growth-oriented. Unlike other resources human resources have rather unlimited possible capabilities. The potential can be used only by creating a climate that can continuously identify, bring to surface, nurture and use the capabilities of people. Human resources development (HRD) system aims at creating such a climate. A number of HRD techniques have been developed in recent years to perform the above task based on certain principles.

\section{Conception Of Hrd:-}

Ever more, more importance is being given to "people" in organizations. This is mainly because organizations are realized that human assets are most important of all assets. This importance can also be partly attributed to the new emerging values of humanism and humanization. Moreover, with the increased importance on creativity, and autonomy, which people are increasingly acquiring and enjoying in the society, the expectations of people are fast changing. People cannot be taken for granted any more. 
In the past, people working in organizations were given attention merely in administering the necessary conditions of work. The established conception of employee's management was based on a very narrow view of person incentive The basic assumption underlying that view was that human beings are primarily motivated by comforts and salary, and necessary attention may be given to rationalize these, so that people do not get dissatisfied. Most of the attention, therefore, was on administration of salary and other benefits. It is now being increasingly realized that people working in organizations are human beings. they have their own needs, motivation and expectations, and that their contribution to the contribution to the organization is much more than that of other

\section{Meaning:-}

"The field of HRD spans several functions across the organization starting with employee recruitment and training, appraisals and payroll and extending to the recreational and motivational aspects of employee development".

The field of HRD or Human Resource Development encompasses several aspects of enabling and empowering human resources in organization. Whereas earlier HRD was denoted as managing people in organizations with emphasis on payroll, training and other functions that were designed to keep employees happy, the current line of management thought focuses on empowering and enabling them to become employees capable of fulfilling their aspirations and actualizing their potential. This shift in the way human resources are treated has come about due to the prevailing notion that human resources are sources of competitive advantage and not merely employees fulfilling their job responsibilities. The point here is that the current paradigm in HRD treats employees as value creators and assets based on the RBV or the Resource Based View of the firm that has emerged in the SHRM (Strategic Human Resource Management) field.

Indeed, one reason for the emergence of the RBV or the SHRM paradigm is that with the advent of the service sector and the greater proportion of companies in the service sector, employees are not merely a factor of production like land, labor and capital but in fact, they are sources of competitive advantage. This is characterized by many CEO's calling employees their chief assets and valuing their contribution accordingly. As a matter of fact, many IT and Financial Services companies routinely refer to employees as the value creators and value enhancers rather than just resources doing their job.

Human Resource Development (HRD) means to develop available manpower through suitable methods such as training, promotions, transfers and opportunities for career development. HRD programmes create a team of welltrained, efficient and capable managers and subordinates. Such team constitutes an important asset of an enterprise. One organization is different from another mainly because of the people (employees) working therein. According to Peter F. Druker, "the prosperity, if not the survival of any business depends on the performance of its managers of tomorrow." The human resource should be nurtured and used for the benefit of the organization.

The field of HRD now has taken on a role that goes beyond employee satisfaction and instead, the focus now is on ensuring that employees are delighted with the working conditions and perform their jobs according to their latent potential which is brought to the fore. This has resulted in the HRD manager and the employees of the HRD department becoming partners in the organization's progress instead of just yet another line function. Further, the HR managers now routinely interact with the functional managers and the people managers to ensure high levels of job satisfaction and fulfillment. The category of people managers is a role that has been created in many multinational companies like Fidelity and IBM to specifically look into the personality related aspects of employees and to ensure that they bring the best to the table.

Finally, HRD is no longer just about payroll or timekeeping and leave tracking. On the other hand, directors of HRD in companies like Infosys are much sought after for their inputs into the whole range of activities spanning the function and they are expected to add value rather than just consume resources. With this introduction, we will be moving into the module covering HRD with each aspect of the HRD function and the associated topics being covered here.

\section{Objectives:-}

1. Work Opportunity: HRD provides an opportunity and a systematic framework for the development resource in the organisation for full expression of their talents.

2. Development of Traits: HRD is associated with the development of total personality so that these can show and use their talent for the benefit of the organisation. 
3. Ability development: HRD makes capable employees. Thus they can develop their capability by which they can do their present job easily.

4. Creative Motivation: HRD manager motivates employees and improve their level of performance.

5. Good Relation: HRD manager stresses the need of coordination which is used for the benefits of him and for the benefits of those who come in his/their touch.

6. Develop team spirit: HRD manager develops the spirit of teamwork; team work for it is used for the effective cooperation and coordination of each employee which ultimately checks industrial unrest.

7. Organisational Growth: HRM manager is responsible for developing health, culture and effective work plan which always result in more profitability.

8. Human Resource Information: HRM manager in general keeps all records to employees working in his organisation; these can be used at any time when these are needed.

Features Of Human Resource Development:-

Training and Development: HRD involves training and developing the employees and managers. It improves their qualities, qualifications and skills. It makes them more efficient in their present jobs. It also prepares them for future higher jobs.

Organizational Development (OD): HRD also involves Organizational Development. OD tries to maintain good relations throughout the organization. It also solves problems of absenteeism, internal conflicts, low productivity and resistance to change

Career Development:HRD also involves career planning and development of employees. It helps the employees to plan and develop their careers. It informs them about future promotions and how to get these promotions. So HRD helps the employee to grow and develop in the organization.

Performance Appraisal:HRD conducts Performance Appraisal, Potential Appraisal, etc. It informs the employees about their strengths and weaknesses. It also advises them about how to increase their strengths and how to remove their weaknesses.

Multidisciplinary:HRD is multidisciplinary. That is, it uses many different subjects. It uses education, management, psychology, communication, and economics. HRD uses all these subjects for training and developing the employees.

Key Element for solving problems: Now-a-days an organization faces many different problems. These problems are caused due to the economic, technological and social changes. These problems can be solved only by knowledge, skill and creative efforts. This knowledge, skill, etc. is achieved from HRD. Therefore, HRD is a key element for solving problems in the organization.

Continuous in Nature: HRD is not a one time affair. It is a continuous process. Development of human resources never stops. This is because continuous changes happen in the organization and environment.

\section{Integrated Use Of Sub-System:-}

HRD system involves the integrated use of sub-systems such as performance appraisal, potential appraisal, career planning, training, etc.

Placement:- HRD places the right man in the right job. Placement is based on performance appraisal, potential appraisal, training, etc. Proper placement gives satisfaction to the employee, and it increases the efficiency.

Promotions and Transfer:- HRD also gives promotions and transfers to the employees based on performance appraisals, etc.

Motivation by Rewards:- HRD also motivates the employees by giving those rewards for performing and behaving better, suggesting new ideas, etc. Financial and non-financial rewards are given.

\section{The Need For Hrd:-}

HRD is needed by any organization that wants to be dynamic and growth-oriented or to succeed in a fast-changing environment. Organizations can become dynamic and grow only through the efforts and competencies of their human resources.

1. Business And Economics Changes:- HRD can be 'a platform for organizational transformation, a mechanism for continuous organizational and individual renewal and a vehicle for global knowledge transfer'.

2. Technological Changes:- Technological change creates requirements for training and development. 
3. Organisational Change:- Organizations that work in less time will have a competitive advantage. A customer and quality focus will permeate tomorrow's superior organization. The arena for an organization's planning and action will be global. Business strategies now depend on quality and versatility of the human resource. Work structure and design will change dramatically.

4. Social, Legal \& Other Changes:- Social attitudes, legal requirements, industrial relations and so on generate training and development needs. They demand new skills in the workplace

\section{Benefits Of Hrd:-}

Human Resource is the most Important and vital Factor of Economic Development or it can be said that humans are the agents of development. Some of the importance of Human Resource or Human Capital is:-

\section{People Commitment :-}

Organizations that embrace the fundamentals of HRD realize the importance of their human resources and focus their efforts on providing employee security; choosing, hiring, training and retaining the right people for the right tasks; rewarding and valuing employee effort; providing fringe benefits, salary raises bonuses and the like; and providing a degree of employment security. Employees whose basic personal and development needs are met are committed employees, who translate the positive effects of HRD efforts into improved productivity.

\section{Improved Employee Performance and Learning Capacity:-}

Patricia McLagan in the book "Models for HRD Practice," defines HRD as "the integrated use of training and development, career development and organizational development to improve individual and organizational effectiveness." According to this and similar definitions, the main focus of human resource development lies in training and enhancing the capabilities of employees. Organizations that strongly focus on training and improving the skills, values, attitudes, perspectives and knowledge of their workforce are more likely to retain employees that utilize their full potential and contribute it to the benefit of the organization. According to Swart et al. in the book "Human Resource Development: Strategy and Tactics," HRD activities decreases staff turnover by 7.05 percent annually.

\section{Improved Organizational Effectiveness:-}

According to C. S. Lakshmi in the book "Human Resource Development In Public Enterprises," human resource development improves organizational effectiveness. Trained and talented employees contribute directly to the effectiveness of an organization. HRD focuses on continually motivating and improving the competencies, dynamism and effectiveness of its employees; developing positive attitudes and problem solving skills; upgrading individual and collective experience, knowledge and perceptions; and enhancing their competitive skills. These and similar activities fine-tune employees to align and integrate their personal goals with organizational goals.

\section{Improved Communication and Involvement:-}

According to Juani Swart et al., HRD improves intra-organizational communication and employee involvement. HRD practices are committed to measuring and continually improving the organizational culture, enhancing teamwork, and improving involvement and participation activities.

\section{Country Develops if The Human Resource is Developed:-}

To enhance economic development the state constructs roads, buildings bridges, dams, power houses, hospitals, etc. to run these units doctors, engineers, scientist, teachers, are required. So if the state invests in a human resource it pays dividend in response.

\section{Increase in Productivity:-}

The batter education, improved skills, and provision of healthy atmosphere will result in proper and most efficient use of resources (non-natural \& natural) which will result in increase in economic production.

\section{Eradication of Social and Economic Backwardness:-}

Human Resource development has an ample effect on the backwardness economy and society. The provision of education will increase literacy which will produce skilled Human Resource. Similarly provision of health facilities will result in healthy Human Resource which will contribute to the national economic development. 


\section{Entrepreneurship Increase:-}

Education, clean environment, good health, investment on the human resource, will all have its positive effects. Job opportunities would be created in the country. And even business environment will flourish in the state which creates many job opportunities.

\section{Social Revolution:-}

Because of Human Resource development the socio economic life of the peoples of a country changes drastically. Over all look changes thinking phenomena changes, progressive thoughts are endorsed in to the minds of peoples.

\section{Conclusion:-}

The organisational effectiveness can be reflected through better quality, higher productivity, cost reduction, higher profits and more EPS (earning per shares) and more market price of shares. This explains the increased role of HRD managers in modern industrial organisations which are working in the most uncertain social, political, economical, technological and international complex and competitive environment.

Finally, HRD is no longer just about payroll or timekeeping and leave tracking. On the other hand, directors of HRD in companies like Infosys are much sought after for their inputs into the whole range of activities spanning the function and they are expected to add value rather than just consume resources. With this introduction, we will be moving into the module covering HRD with each aspect of the HRD function and the associated topics being covered here. It is hoped that the readers would gain an overall perspective about HRD after going through the HRD module.

\section{References:-}

1. Joint Learning Initiative. Human resources for health: overcoming the crisis. Cambridge: Global Equity Initiative, Harvard University; 2004.

2. Kolehmainen-Aitken RL. Decentralization's impact on the health workforce: Perspectives of managers, workers and national leaders. Hum Resour Health 2004; 2: 5- doi: 10.1186/1478-4491-2-5 pmid: 15144558.

3. Chopra M, Munro S, Lavis JN, Vist G, Bennett S. Effects of policy options for human resources for health: an analysis of systematic reviews. Lancet 2008; 371: 668-74 doi: 10.1016/S0140-6736(08)60305-0 pmid: 18295024

4. Task Force on Health Systems Research. Informed choices for attaining the Millennium Development Goals: towards an international cooperative agenda for health-systems research. Lancet 2004; 364: 997-1003 doi: 10.1016/S0140-6736(04)17026-8 pmid: 15364193.

5. Sutherland K, Leatherman S. Regulation and quality improvement: a review of the evidence. London: The Health Foundation; 2006.

6. Thomson O'Brien MA, Freemantle N, Oxman AD, Wolf F, Davis DA, Herrin J. Continuing education meetings and workshops: effects on professional practice and health care outcomes. Cochrane Database Syst Rev 2001; 2: CD003030- pmid: 11406063.

7. O’Brien MA, Rogers S, Jamtvedt G, Oxman AD, Odgaard-Jensen J, Kristoffersen DT, et al., et al. Educational outreach visits: effects on professional practice and health care outcomes. Cochrane Database Syst Rev 2007; 4: CD000409- pmid: 17943742.

8. Ensor T, Weinzierl S. Regulating health care in low- and middle-income countries: Broadening the policy response in resource constrained environments. Soc Sci Med 2007; 65: 355-66 doi: 10.1016/j.socscimed.2007.03.021 pmid: 17451853.

9. P .SUBBARAO- HUMAN RESOURCE MANAGEMENT. 